\title{
NUTRACEUTICALS FROM FRESHWATER MICROALGAE
}

\author{
ArchanaTiwari*, VandanaSingh, Neha Thakur \\ School of Sciences, Noida International University, Greater Noida, Uttar Pradesh, India.
}

\begin{abstract}
Microalgae are excellent reservoirs of adiverse range of nutraceuticals. The presence of secondary metabolites, pigments, vitamins makes microalgae unique reservoir of nutraceuticals. Many strains of microalgae are known to produce intracellular and extracellular metabolites with diverse biological activities such as antibacterial and antifungal;in addition, to it, they are also rich in adiverse range of antioxidants, vitamins and pigments. There is a drastic increase in cases of antibiotic resistance and exploring the antimicrobial efficacy of microalgae can aid in resolving the problem. In this study we have investigated the activity of Microalgae Anabaena variabilis, Synechococcus elongates andSpirulinaplatensisagainst the human pathogenic bacteria namely Enterococcus sp, Esherichiacoli, Pseudomonas sp, Klebsiella sp.Experimental results show that microalgal extracts are capable of inhibiting the growth of pathogenic bacterial strains. Methanol (60\%) extract of Anabaena variabilisgave $30 \mathrm{~mm}$ zone of inhibition against E.coliand methanol extract of Synechococcus elongates gave the highest antimicrobial activity against Enterococcus (32mm inhibition zone) and Pseudomonas sp. (26mm inhibition zone). S.platensis shows highest antimicrobial activity against E.coliwith Methanol (100\%). As per the formation of zones, ethanol (100\%) extract, butanol, water, acetone and methanol (100\%) extract gave a high visibility of zone of inhibition. Exploring the nutraceutical efficacy of microalgae can efficiently address theplethora of drug related issues and, in addition, serve as asource of nutrients.
\end{abstract}

Keywords: Nutraceutical, Microalgae, Antimicrobial activity,antibiotic resistance.

\section{INTRODUCTION}

Microalgae are unique reservoirs of nutraceuticals and produce a potential source of biologically active secondary metabolites, which are compounds that are essential for cell metabolism ${ }^{9}$. The nutraceutical efficacy of the microalgal strains is by virtue of the diverse metabolites, antioxidants enzymes ${ }^{1,2}$, pigments and vitamins, present in these extraordinary photosynthetic microbes.Many of these compounds possess antibiotic and pharmacological effects such as toxicity for eukaryotic organismsantibacterial ${ }^{3}$, antifungal ${ }^{11}$, antiviral $^{17}$. The high portion of the antimicrobial producing strains may be associated with an ecological role, playing a defensive action to maintain their niche, or enabling the invasion of strain into an established microbial community.Allelopathyis defined as the release of chemicals or toxins by plants or microorganisms, thataffect their potential competitors for resources ${ }^{18,12}$. It is a ubiquitous phenomenon in theaquaticecosystem, and there are diverse organisms involved like angiosperms, macrophytes, and macroalgae. According to Molisch $^{14}$, allelopathy covers biochemical *Corresponding author: Email:panarchana@gmail.com

http://dx.doi.org/10.20530/IJTA $32 \quad 5-10$

ISSN 2320-138X @ 2016 interactions, both stimulatory and inhibitory, among different primaryproducers or between primary producers and microorganisms. Freshwater microalgae are rich in several bioactive secondary metabolites with diverse chemical structure, which may achieve high concentrations in the aquatic medium when microalgal blooms. Some of the compounds released by microalgae have phytoplankton or aquatic plants.

Extracellular components from cultures of "dominant" microalgae have been reported to be isolated indicating the clear effect of extracellular components in the succession of microalgal populations $^{9,}{ }^{21}$. Subsequent studies have continued to support the role that these allelochemicals in controlling annual variability in phytoplankton communities. Microalgae are one of the richest sources of known and novel bioactive compounds including toxins with wide pharmaceutical applications. Many compounds from microalgae are useful for thewelfare of humanity. Microalgae have been identified as a rich source of biologically active compounds with antiviral, antiplasmodial, antibacterial,antifungal and many more activities ${ }^{20}$. Marine microalgae can serve as anexcellent source of large scale production of vitamins like Vitamin $\mathrm{E}$ and Vitamin B complex. The pigments like carotenoid and phycobiliprotein extracted from microalgae find wide commercial applications as feed additives, as colouring agents, as drugs and in thecosmetic industry. 


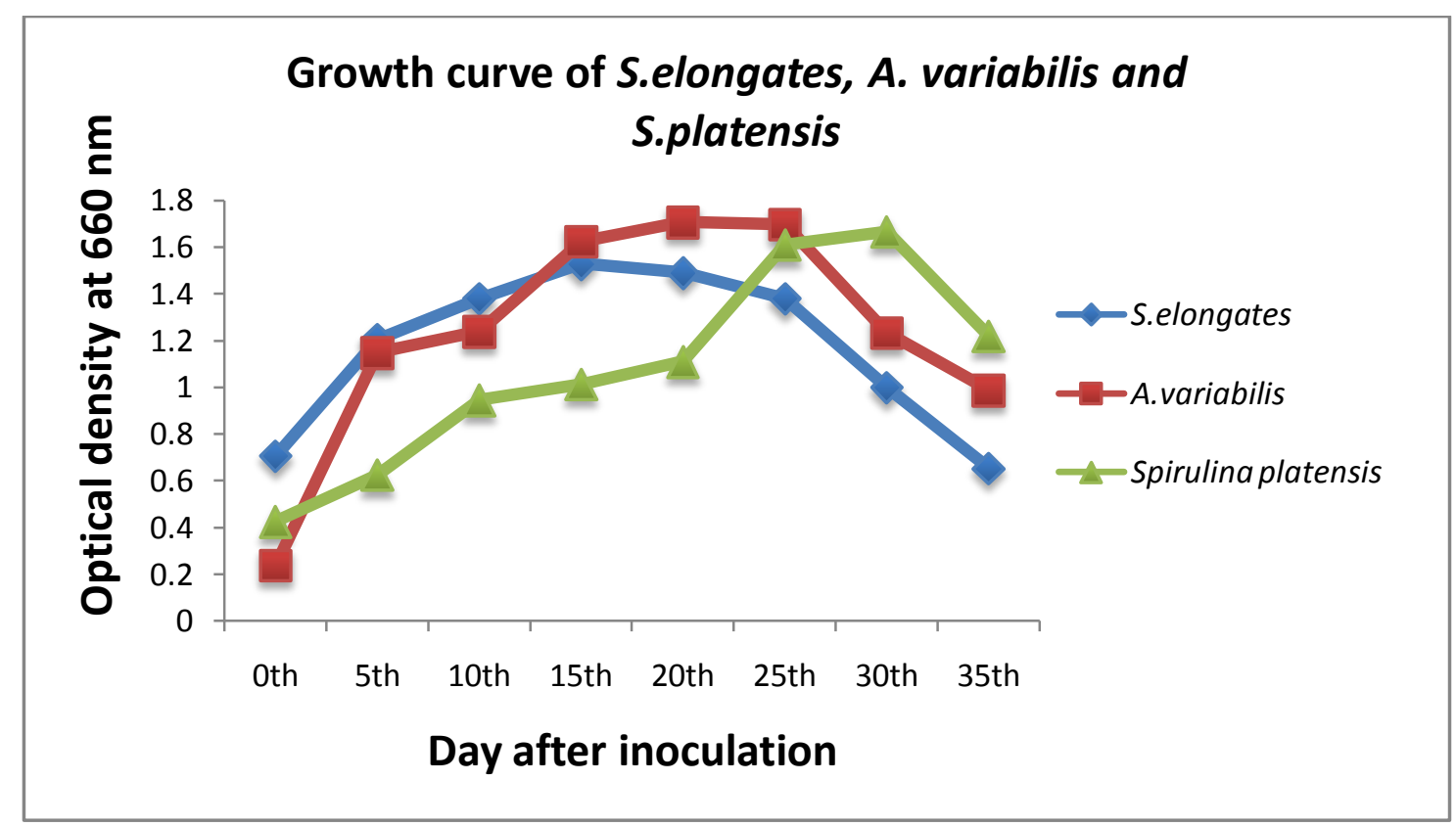

Graph 1- Growth curve of Microalgae

Table 1: Antibacterial activity of Anabaena variabilis

\begin{tabular}{lcccc}
\hline \multicolumn{1}{c}{ Extracts } & E.coli & Pseudomonas sp & Enterococcus sp & Klebsiellasp \\
\hline Methanol (60\%) & - & $22 \pm 1.8 \mathrm{~mm}$ & $19 \pm 0.8 \mathrm{~mm}$ & $32 \pm 2.6 \mathrm{~mm}$ \\
Methanol (80\%) & $32 \pm 2.8 \mathrm{~mm}$ & - & - & $21 \pm 1.9 \mathrm{~mm}$ \\
Ethanol & $33 \pm 2.4 \mathrm{~mm}$ & $18 \pm 1.2 \mathrm{~mm}$ & $29 \pm 1.9 \mathrm{~mm}$ & - \\
Butanol & $26 \pm 1.9 \mathrm{~mm}$ & $22 \pm 2.1 \mathrm{~mm}$ & $30 \pm 2.7 \mathrm{~mm}$ & $25 \pm 1.8 \mathrm{~mm}$ \\
Control & $34 \pm 2.4 \mathrm{~mm}$ & $31 \pm 1.8 \mathrm{~mm}$ & $33 \pm 2.8 \mathrm{~mm}$ & $30 \pm 2.6 \mathrm{~mm}$ \\
\hline
\end{tabular}

The aim of thestudy reported here is to investigate the nutraceutical potential of three freshwater microalgae as anantibacterial agent against the bacteria of clinical significance.

\section{MATERIALS \& METHODS}

\section{MicroalgalCultures}

Microalgal strains were isolated from anearby pond and identified as $A$. variabilis, S. elongates andS.platensisas pertaxonomicclassification. The purified cultures were grown in BG11 medium and kept at optimum conditions.

\section{Bacterial Cultures}

Four pathogenic strains namely E.coli, Enterococcus sp, Pseudomonas sp, and Klebsiellasp,were isolated and cultivated. These isolated strains were cultivated on nutrient agar media and were incubated at $37^{\circ} \mathrm{C}$ for 24 hours.

\section{Growth Estimation of Microalgal Cultures}

Cultures were harvested on $16^{\text {th }}$ day, and optical density was observed in every $5^{\text {th }}$ day at O.D. $(660 \mathrm{~nm})$ of the incubation period.

\section{Estimation of Phenolic content}

Estimation of phenolic content was done by FolinCiocalteu reagent ${ }^{13}$. Dilute extract of microalgae was mixed with FolinCiocalteu reagent $(5 \mathrm{ml}, 1: 10$ diluted with distilled water) and aqueous $\mathrm{Na}_{2} \mathrm{CO}_{3}(4 \mathrm{ml}, 1 \mathrm{M})$. The mixtures were allowed to stand for 15 minutes, and the total phenols were determined by colorimetry at $765 \mathrm{~nm}$.

\section{Estimation of Polysaccharides}

The polysaccharide content was determined using Phenol-sulfuric -acid method ${ }^{4}$. The concentration of polysaccharides was estimated by harvesting cells and extracting with water $(0.5$ $\mathrm{ml}$ ). The supernatant was discarded, and $4 \mathrm{M} \mathrm{NaOH}$ was added. Initially, it was washed with $100 \%$ ethanol and later $90 \%$ ethanol was added to the supernatant followed bycentrifugation. Later on, $4 \mathrm{M} \mathrm{NaOH}$ was added to the precipitate and kept for 1 hour.10\% TCA was added to the supernatant and kept overnight. 
Table 2: Antibacterial activity of Synechococcuselongates

\begin{tabular}{|c|c|c|c|c|c|}
\hline Extracts & E.coli & Enterococcus sp. & Pseudomonas sp. & Klebsiella & sp. \\
\hline Ethanol & $15 \pm 0.21 \mathrm{~mm}$ & $25 \pm 1.5 \mathrm{~mm}$ & $11 \pm 0.7 \mathrm{~mm}$ & \multicolumn{2}{|c|}{$10 \pm 0.6 \mathrm{~mm}$} \\
\hline Methanol (60\%) & $23 \pm 0.9 \mathrm{~mm}$ & $20 \pm 1.8 \mathrm{~mm}$ & $8 \pm 0.7 \mathrm{~mm}$ & \multicolumn{2}{|l|}{-} \\
\hline Methanol (80\%) & $26 \pm 1.2 \mathrm{~mm}$ & $21 \pm 1.9 \mathrm{~mm}$ & - & \multicolumn{2}{|l|}{-} \\
\hline Methanol (100\%) & $30 \pm 2.1 \mathrm{~mm}$ & $29 \pm 2.1 \mathrm{~mm}$ & - & \multicolumn{2}{|c|}{$20 \pm 1.1 \mathrm{~mm}$} \\
\hline Water & $18 \pm 1.3 \mathrm{~mm}$ & $17 \pm 0.8 \mathrm{~mm}$ & - & \multicolumn{2}{|l|}{-} \\
\hline Acetone & $22 \pm 1.3 \mathrm{~mm}$ & - & $23 \pm 1.9 \mathrm{~mm}$ & \multicolumn{2}{|c|}{$27 \pm 1.2 \mathrm{~mm}$} \\
\hline Acetic acid & $28 \pm 1.9 \mathrm{~mm}$ & $16 \pm 0.9 \mathrm{~mm}$ & - & \multicolumn{2}{|c|}{$22 \pm 1.9 \mathrm{~mm}$} \\
\hline Butanol & $30 \pm 2.5 \mathrm{~mm}$ & $24 \pm 1.8 \mathrm{~mm}$ & $23 \pm 1.9 \mathrm{~mm}$ & \multicolumn{2}{|l|}{ - } \\
\hline Met:Acetone (1:1) & $9 \pm 0.8 \mathrm{~mm}$ & - & $8 \pm 0.4 \mathrm{~mm}$ & \multicolumn{2}{|c|}{$6 \pm 0.4 \mathrm{~mm}$} \\
\hline But:methanol $(1: 1)$ & $12 \pm 0.9 \mathrm{~mm}$ & $10 \pm 0.8 \mathrm{~mm}$ & $7 \pm 0.4 \mathrm{~mm}$ & \multicolumn{2}{|l|}{-} \\
\hline Ethanol:Acetic acid (1:1) & $14 \pm 0.6 \mathrm{~mm}$ & $9 \pm 0.5 \mathrm{~mm}$ & - & \multicolumn{2}{|l|}{-} \\
\hline Control & $32 \pm 2.5 \mathrm{~mm}$ & $30 \pm 1.8 \mathrm{~mm}$ & $28 \pm 1.5 \mathrm{~mm}$ & \multicolumn{2}{|c|}{$29 \pm 1.9 \mathrm{~mm}$} \\
\hline
\end{tabular}

Table 3: Antibacterial activity of Spirulinaplatensis

\begin{tabular}{|lcccc|}
\hline Extracts & E.coli & Pseudomonas sp & Enterococcus sp & Klebsiellasp \\
\hline Methanol (60\%) & $25 \pm 1.8 \mathrm{~mm}$ & - & $32 \pm 2.8 \mathrm{~mm}$ & $19 \pm 0.8 \mathrm{~mm}$ \\
\hline Methanol (80\%) & $28 \pm 2.1 \mathrm{~mm}$ & $26 \pm 1.8 \mathrm{~mm}$ & $27 \pm 1.2 \mathrm{~mm}$ & - \\
\hline Ethanol & - & $20 \pm 1.2 \mathrm{~mm}$ & - & $25 \pm 1.8 \mathrm{~mm}$ \\
\hline Butanol & $29 \pm 1.8 \mathrm{~mm}$ & $30 \pm 2.1 \mathrm{~mm}$ & $26 \pm 2.1 \mathrm{~mm}$ & - \\
\hline Control & $33 \pm 2.4 \mathrm{~mm}$ & $34 \pm 1.9 \mathrm{~mm}$ & $35 \pm 2.8 \mathrm{~mm}$ & $30 \pm 2.5 \mathrm{~mm}$ \\
\hline
\end{tabular}

-=No inhibitory effect; width 1 to $3 \mathrm{~mm}=$ weak activity; width 8 to $15 \mathrm{~mm}=$ moderate activity; width $>15 \mathrm{~mm}$

= strong activity.

Table 4: Phenol and Polysaccharide content in Cyanobacterial extracts

\begin{tabular}{lll}
\hline Microalgae & Phenol & Polysaccharide \\
\hline Anabaena variabilis & $25.12 \pm 0.28 \mathrm{mg} / \mathrm{g}$ & $80 \pm 1.9 \mu \mathrm{g}$ \\
Spirulinaplatensis & $33.4 \pm 0.83 \mathrm{mg} / \mathrm{g}$ & $150 \pm 2.5 \mu \mathrm{g}$ \\
Synechococcuselongates & $25.35 \pm 1.2 \mathrm{mg} / \mathrm{g}$ & $120 \pm 3.8 \mu \mathrm{g}$ \\
\hline
\end{tabular}

\section{Estimation of Antibacterial activity}

The antibacterial activity of microalgal extracts was evaluated by agar plate diffusion test and disc method.

\section{AGAR PLATE METHOD (cup plate method)}

In this technique wells are made in the agar plates by using a screw cork of approximately $10 \mathrm{~mm}$ diameter.The wells were then filled with the microalgal extracts using a micropipette. The Petri plates were then covered, sealed and incubated at a temperature of $26^{\circ} \mathrm{C}$ for a period of 48-72 hours. The plates were then analyzed for their antimicrobial activity on the basis of formation of azone of inhibition.

\section{DISC METHOD}

In this technique, small discs were cut out from WATTMAN FILTER PAPER having a diameter $(8 \mathrm{~mm})$.These discs were sterilized and were soaked in microalgal extracts for around twenty minutes and were allowed to dry. These discs were then placed in the Petri plates and were incubated at a room temperature of $26^{\circ} \mathrm{C}$ for $48-72$ hours in anincubator.

\section{RESULTS \& DISCUSSION}

Many microalgae produce compounds with potent biological activities. A number of highly potent microalgal natural products have been uncovered as potential lead compounds for further drug development. In this research, microalgae were collected and cultured in BG11 medium. Spectrophotometrical analysis of the microalgal strains at $660 \mathrm{~nm}$ by culturing them in BG-11 media depicted the growth. It was observed that Spirulinaplatensis showed maximum growth after the $25^{\text {th }}$ day. Whereas A.variabilis attained its maximum growth after the $20^{\text {th }}$ day and in 
S.elongates it was after the $15^{\text {th }}$ day, indicating the fast growth of S. elongates(Fig. 1).

Based on their growth characteristics, three species were selected for the production of antimicrobial agents against pathogenic organisms like E.coli, Pseudomonas sp., Enterococcus sp., Klebsiella sp.Experimental results show that microalgal extracts are capable of inhibiting the growth of pathogenic bacterial strains. Methanol (60\%) extract of Anabaena variabilisgave $30 \mathrm{~mm}$ zone of inhibition against E.coli(Table 1), and methanol extract of Synechococcus elongates gave the highest antimicrobial activity against Enterococcus (32mm inhibition zone) and Pseudomonas sp. (26mm inhibition zone)as shown in Table 2. S.platensis shows highest antimicrobial
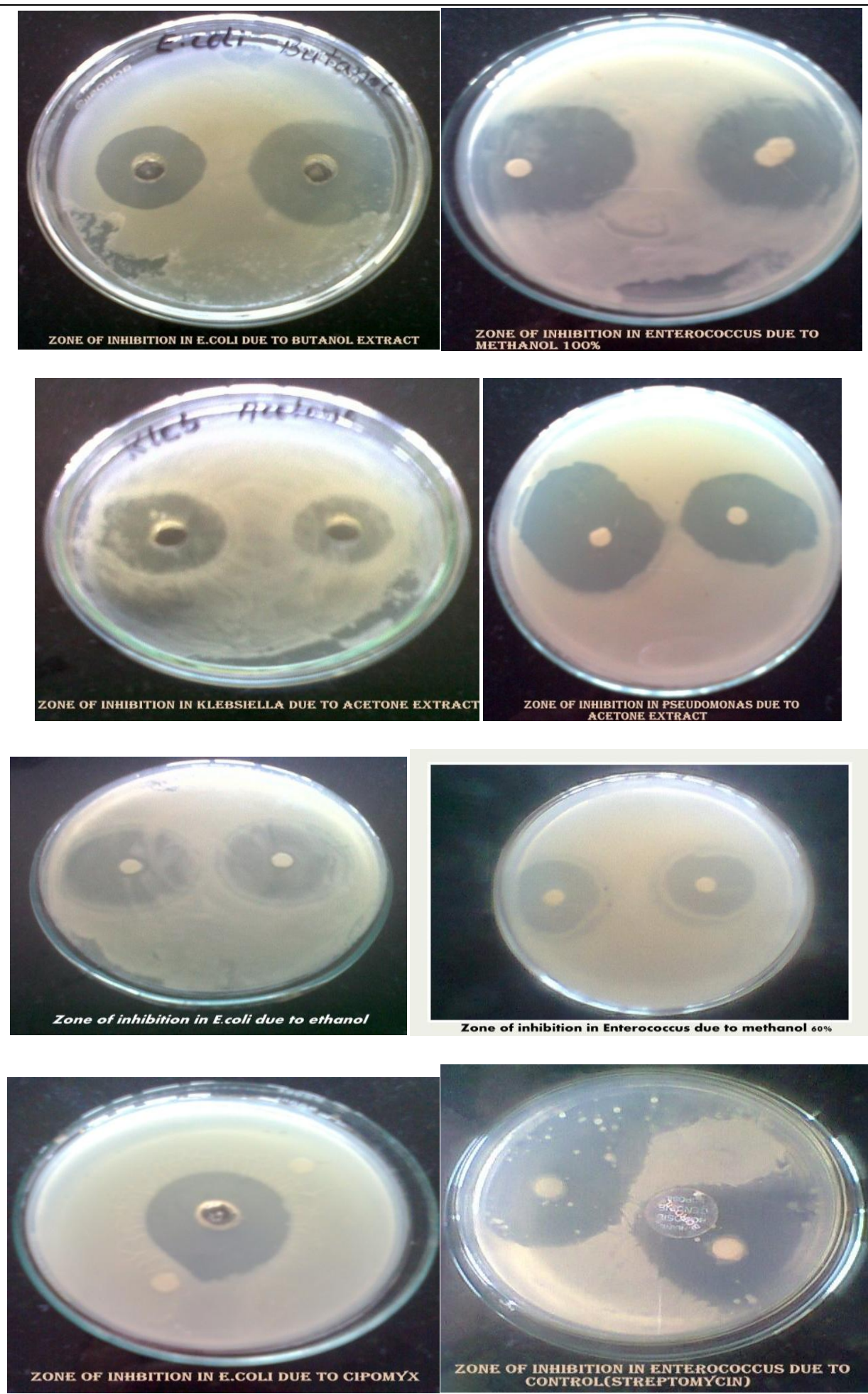

Figure 1: Antibacterial activity of Microalgal Extracts. 
activity (Table 3) against E.coliwith Methanol $(100 \%)$. As per the formation of zones, ethanol $(100 \%)$ extract, butanol, water, acetone and methanol (100\%) extract gave a high visibility of zone of inhibition as compared to remaining ones (Figure 1).

As microalgae are very resistant to extreme environmental conditions, they are assuming increasing importance in frontier areas of biotechnology. Microalgae produce potent toxins, but they also produce useful bioactive compounds, including substances with antitumor, antiviral, anticancer, antibiotic and antifungal activity, UV protectants and specific inhibitors of enzymes ${ }^{20}$. There are reports on antimicrobial effects from microalgal aqueous and organic solvent extractand have been visualized in bioassays using selected microorganisms. In the investigations, microalgae have demonstrated the antimicrobial effects of many strains likeNostoc, Anabaena, Synechococcus, Oscillatoriaagainst a variety of microbes. Kim $^{10}$ showed that $50 \%$ of the microalgae genera existed in heterocytous filament form. A total of 100 such samples were taken against 10 different strains of fungi and proved to have fungicidal activity. The unusual metabolites produced by the microalgae have been visualized as either or as products of pharmaceutical importance.Vardi ${ }^{21}$ reported the allelopathic relationship between microcystin-producing Microcystis sp. and the dinoflagellate, Peridinium gatunense in the mesotrophic Sea of Galilee. The compounds responsible for the allelopathic response can be attributed to microcystins. The antimicrobial substances involved may target various kinds of microorganisms, prokaryotes as well as eukaryotes.

Phenol and Polysaccharide concentration was observed maximum inS.platensis as compared to A. variabilis and S.elongates. The phenol and polysaccharide content in S.platensis was 33.4 $\mathrm{mg} / \mathrm{g}$ and $150 \mu \mathrm{g}$ respectively whereasin S.elongates it was $25.35 \mathrm{mg} / \mathrm{g}$ and $120 \mu \mathrm{g}$ (Table 4). It was very low in A.variabilis that is $25.12 \mathrm{mg} / \mathrm{g}$ and $80 \mu \mathrm{g}$. Microalgal production of extracellular polymers, mainly EPS is well documented (De Phillips et al., 1998). Exopolysaccharides (EPS) have been reported to play a significant role in providing protection to the cell and also act as antimicrobial agents.

Blue greenmicro algae (Microalgae) can act as a source of novel, biologically active compounds such as phycobilins, phenols, (antioxidants) terpenoids, steroids and polysaccharides. The occurrence of phenolic compounds in microalgae is less documented than that in higher plants. Algal phenolic compounds were reported to be potential antioxidants to combat free radicals, which are harmful to our body and food systems. Several epidemiological studies revealed that phenolic compounds present in thediet are helpful in treating coronary heart disease and osteoporosis stroke and other degenerative diseases. Furthermore, phenols have been reported to exhibit pharmacological properties such as ananticarcinogenic, antiviral, antimicrobial, anti-inflammatory or anti-tumor.

De Phillips $^{6}$ has reported the production of extracellular polymers, mainly EPS in microalgae. Polysaccharides play a diverse role in nature and get modified under stress condition ${ }^{16}$. Caiola ${ }^{5}$ have reported the important role of Exopolysaccharides (EPS) by actings as protecting layer in the cell boundary. They also play a role in soil aggregation because they possess gluing properties ${ }^{15}$. There have been reports on the presence of functional groups on EPS, contributing to the binding of heavy metals ${ }^{8,19}$.

Microalgae are also used in aquaculture, wastewater treatment, food, fertilizers, and production of secondary metabolites including exopolysaccharides, vitamins, toxins, enzymes and pharmaceuticals. Future research should focus on isolating new microalgalstrains capable of yielding high-value products and methods to enhance the productivity of these products through genetic engineering.Optimization of incubation conditions and fermenter designs in order to increase productivity are essential for the large-scale industrial production of themicroalgal products.

\section{REFERENCES}

1. Tiwari A. \& Thakur A. Antioxidative activity of Superoxide Dismutase in bloom forming cyanobacteria. International Journal of Pharma and Biosciences. 2013; 4(1): 562-569. http://www.ijpbs.net/vol-4/issue-1/bio/65.pdf

2. Tiwari A. \& Shivani. Antioxidative Potential of Catalase in Bloom Forming CyanobacteriaAnabaena variabilis and Synechococcuselongates. International Journal of Pharma and Biosciences. 2012 July; 3(3): 956-966. http://www.ijpbs.net/vol3/issue-3/bio/108.pdf

3. Bloor S, England RR. Antibiotic production by the cyanobacteriumNostocmuscorum. Journal of Applied Phycology. 1989 Dec;1(4):367-72. Available from: http://dx.doi.org/10.1007/bf00003474.

4. BUYSSE J, MERCKX R. An Improved Colorimetric Method to Quantify Sugar Content of Plant Tissue. Journal of Experimental Botany. 1993;44(10):1627- 
9. Available from: http://dx.doi.org/10.1093/jxb/44.10.1627.

5. Caiola MG, Billi D, Friedmann El. Effect of desiccation on envelopes of the cyanobacterium Chroococcidiopsis sp. (Chroococcales). European Journal of Phycology. 1996 Feb;31(1):97-105. Available from: http://dx.doi.org/10.1080/09670269600651251.

6. De Philippis $R$, Vincenzini $M$. Exocellular polysaccharides from cyanobacteria and their possible applications. FEMS Microbiol Rev. 1998 Sep;22(3):151-75. Available from: http://dx.doi.org/10.1111/j.15746976.1998.tb00365.x.

7. Dodds WK, Gudder DA, Mollenhauer D. THE ECOLOGY OF NOSTOC. J Phycol. 1995 Feb;31(1):218. Available from: http://dx.doi.org/10.1111/j.00223646.1995.00002.x.

8. Caglioti E, Loreto V. Dynamical properties and predictability of a class of self-organized critical models. Phys Rev E. 1996 Mar 1;53(3):2953-6. Available from: http://dx.doi.org/10.1103/physreve.53.2953.

9. KEATING KI. Allelopathic Influence on Blue-Green Bloom Sequence in a Eutrophic Lake. Science. 1977 May 20;196(4292):885-7. Available from: http://dx.doi.org/10.1126/science.196.4292.885.

10. Kim J-D. Screening of Cyanobacteria (Blue-Green algae) from Rice Paddy Soil for Antifungal Activity against Plant Pathogenic Fungi. Mycobiology. 2006;34(3):138. Available from: http://dx.doi.org/10.4489/myco.2006.34.3.138.

11. Kulik MM. The potential for using cyanobacteria (blue-green algae) and algae in the biological control of plant pathogenic bacteria and fungi. European Journal of Plant Pathology. 1995 Nov;101(6):585-99. Available from: http://dx.doi.org/10.1007/bf01874863.

12. Lampert, W., Sommer, U Limnoecology: The ecology of lakes and Streams. Oxford University Press, New York. 1997; limno.fcien.edu.uy/pdf/Limnoecology.pdf

13. McDonald S, Prenzler PD, Antolovich M, Robards K. Phenolic content and antioxidant activity of olive extracts. Food Chemistry. 2001 Apr;73(1):73-84. Available from: http://dx.doi.org/10.1016/s03088146(00)00288-0.

14. Molisch, H. Der EinflusseinerPflanzeauf die andereAllelopathie. Fischer, Jena, 1937.

15. Nisha R, Kaushik A, Kaushik CP. Effect of indigenous cyanobacterial application on structural stability and productivity of an organically poor semi-arid soil. Geoderma. 2007 Feb;138(1-2):49-56. Available from:

http://dx.doi.org/10.1016/j.geoderma.2006.10.007

16. Ozturk S, Aslim B. Modification of exopolysaccharide composition and production by three cyanobacterial isolates under salt stress. Environ SciPollut Res. 2009 Sep 1;17(3):595-602. Available from: http://dx.doi.org/10.1007/s11356009-0233-2.

17. Patterson GML, Carmeli S. Biological effects of tolytoxin (6-hydroxy-7-0-methyl-scytophycin b), a potent bioactive metabolite from cyanobacteria. Arch Microbiol. 1992 May;157(5):406-10. Available from: http://dx.doi.org/10.1007/bf00249096.

18. Rice, E.L. Allelopathy, 2nd ed. Academic Press, Orlando, FL. 1984; pp. 423.

19. Sharma M, Kaushik A, Somvir, Bala K, Kamra A. Sequestration of chromium by exopolysaccharides of Nostoc and Gloeocapsa from dilute aqueous solutions. Journal of Hazardous Materials. 2008 Sep;157(2-3):315-8. Available from: http://dx.doi.org/10.1016/j.jhazmat.2007.12.100.

20. Tiwari A. Cyanobacteria: Nature, Potentials and applications. Astral International Publishers, New Delhi. 2014; http://www.amazon.in/ Cyanobacteria-Nature-Potentials-ApplicationsArchana-ebook/dp/B00G4CD7XK

21. Vardi A, Schatz D, Beeri K, Motro U, Sukenik A, Levine $A$, et al. Dinoflagellate-Cyanobacterium Communication May Determine the Composition of Phytoplankton Assemblage in a Mesotrophic Lake. Current Biology. 2002 Oct;12(20):1767-72. Available from: http://dx.doi.org/10.1016/s09609822(02)01217-4. 